\title{
Trauma Surgery $\&$ Acute Care Open \\ Optimizing critical care of the trauma patient at the intermediate care unit: a cost-efficient approach
}

\author{
Joost D J Plate, ${ }^{1}$ Linda M Peelen, ${ }^{2,3}$ Luke P H Leenen, ${ }^{1}$ Falco Hietbrink ${ }^{1}$
}

'Division of Surgery, University Medical Centre Utrecht, Utrecht University, Utrecht, The Netherlands

2Julius Centre for Health Sciences and Primary Care Utrecht University, Utrecht, The Netherlands

'Departments of Anesthesiology and Intensive Care Medicine, Utrecht University, Utrecht, The Netherlands

\section{Correspondence to} Joost D J Plate, Division of Surgery, Universitair Medisch Centrum Utrecht, Utrecht 3584CX, Netherlands; j.d.j. plate@umcutrecht.nl

Received 28 August 2018 Revised 13 September 2018 Accepted 17 September 2018

(c) Author(s) (or their employer(s)) 2018. Re-use permitted under CC BY-NC. No commercial re-use. See rights and permissions. Published by BMJ.

To cite: Plate JDJ, Peelen LM, Leenen $\mathrm{LPH}$, et al. Trauma Surg Acute Care Open 2018:3:e000228.

\section{ABSTRACT}

Background The aim of this study was to describe the case load, safety, and cost savings of critical care of the trauma patient provided at the surgical intermediate care unit (IMCU).

Methods This cohort study included all trauma admissions between January 1, 2011 and January 7, 2015 at the general intensive care unit (ICU), standalone neuro(surgical) IMCU, and stand-alone (trauma) surgical IMCU. Trauma mechanism, Abbreviated Injury Scale score and Injury Severity Score (ISS), vital signs, laboratory parameters, admission duration, intubation duration, ICU transfer, and in-hospital mortality were prospectively collected. Hypothetical cost savings were calculated using the fixed cost price per IMCU (US\$1500) and ICU (US\$2500) admission day.

Results A total of 1320 admissions were included, $675(51.1 \%)$ at the IMCU and $645(48.9 \%)$ at the ICU. Patients admitted at the IMCU had a median ISS of $17(11,22)$. Their median duration of admission was 32.8 hours $(18.8,62.5)$. At the IMCU, one patient died due to aneurogenic shock. A subsequent ICU transfer was required in 38 (5.6\%) IMCU admissions. Of these transfers, four patients died due to neurological deterioration. At the ICU, the median ISS was 22 (14, 30). Nearly all ( $n=620,96.3 \%)$ ICU trauma patients required mechanical ventilation. Expected total cost savings due to the presence of the IMCU were US\$1 772 785.

Discussion A substantial amount of trauma patients in need of critical care can safely be admitted at the IMCU, without the need for further mechanical ventilation. Thereby, the IMCU could fulfill an essential cost-saving role in the management of severely injured trauma patients.

Level of evidence Level IV.

\section{INTRODUCTION}

Worldwide introduction of organized trauma systems has led to improved outcomes after injury. ${ }^{12}$ This has been accomplished through an ongoing emphasis on field triage and distance to (Level I) trauma centers, regionalization of trauma care, and efficiency of managing trauma patients within hospitals. ${ }^{13-7}$ One of the downsides of these effective trauma systems is their costs, as expensive trauma resources (eg, intensive care unit (ICU) availability and trauma expertise) need to be readily available 24/7.68 This financial burden has already led to the closure of existing trauma centers, and containing trauma-related costs has therefore become a priority of the American College of Surgeons. ${ }^{19}$
Intermediate Care Units (IMCUs), logistically positioned between the hospital ward and the ICU, carry the potential to reduce this financial burden. Through decreasing the need for costly and sparse ICU beds, fixed costs can likely be reduced due to lower nursing costs. ${ }^{10}$ For this purpose, IMCUs are already increasingly being used in hospitals over the last decade. ${ }^{11}$ An important function herein is as a step-down unit, facilitating in the safe downgrading of (critical) care for ICU patients. ${ }^{12}$ An additional advantage of using IMCUs is found in hospital settings where the ICU is supervised by general intensivists. In these settings, admitting trauma patients at the (specialist supervised) surgical IMCU could have the additional benefit of specialty-specific critical trauma care delivery. ${ }^{13}$

The aim of this study was to describe the caseload, safety, and potential for cost savings of in-hospital trauma critical care at the mixed-surgical, stand-alone IMCU.

\section{METHODS}

\section{Study design and settings}

This observational cohort study was conducted at the University Medical Centre in Utrecht, a tertiary university referral hospital in the Netherlands which serves as a Level 1 trauma center. In this hospital, trauma patients in need of critical care are typically admitted to one out of three units: the stand-alone mixed-surgical IMCU, the stand-alone neurosurgical IMCU, or the general, mixed ICU.

The stand-alone, mixed-surgical IMCU of this hospital admits patients from all surgical disciplines, providing hemodynamic monitoring and cardiovascular and respiratory support including inotropic use and supplementary (high-flow) oxygen. It has a nurse:patient ratio of $1: 1.5$ and has six beds. This IMCU is supervised by trauma surgeons with additional critical care certifications. It does not provide invasive ventilation and continuous renal replacement therapy. Emphasis is on wound and fracture care.

The stand-alone neurosurgical IMCU also provides hemodynamic monitoring and cardiovascular and respiratory support, though does not support inotropic use. Emphasis is on neurological observation. The nurse:patient ratio is also $1: 1.5$ with six beds, and supervision is provided by the neurologists.

The general ICU is led by intensivists of various non-surgical backgrounds and consists of 36 beds and a nurse:patient ratio of $1: 1$. The nurse:patient ratio at the hospital ward was 1:5. All admissions after sustained trauma admitted at one of 
Open access

Table 1 Baseline of trauma admissions at the intermediate and intensive care units

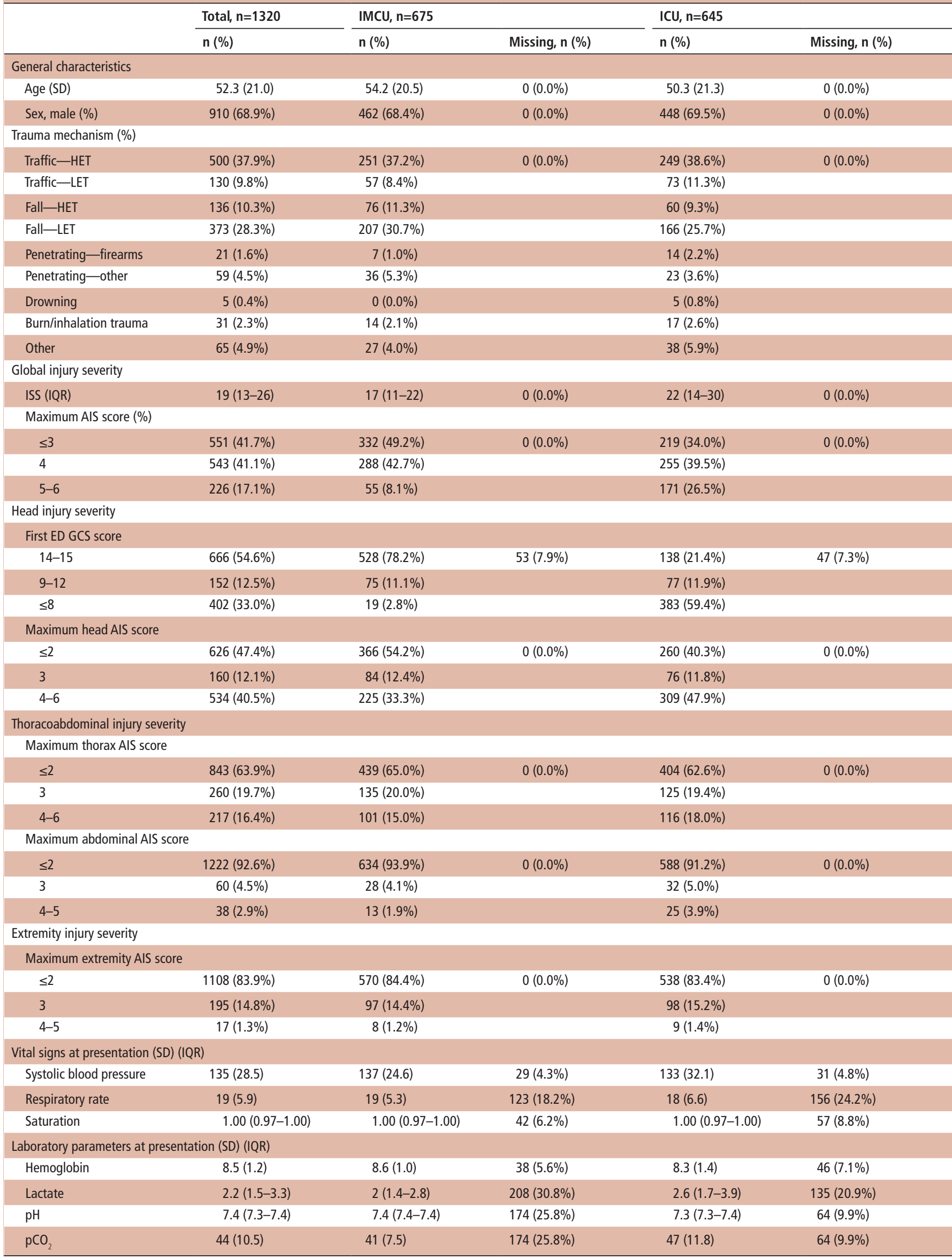


Table 1 Continued

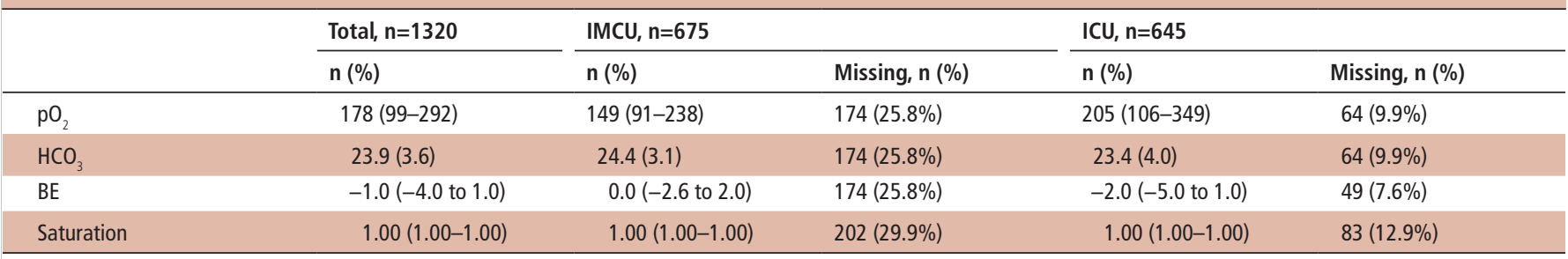

This baseline table shows the overall characteristics of trauma admissions which received critical care during the study period, stratified per location of delivered critical care (intermediate or intensive care unit).

AIS, Abbreviated Injury Scale; BE, base excess; ED, emergency department; GCS, Glasgow Coma Scale; ICU, intensive care unit; IMCU, intermediate care unit; ISS, Injury Severity Score; HET, high energy trauma; LET, low energy trauma; BCA, bootstrapped confidence interval; ICP, Intracranial pressure.

the IMCUs or ICU between January 1, 2011 and January 7, 2015 were included in the study. According to the Institutional Review Board, the study was not subject to the Medical Research Involving Human Subjects Act and therefore the necessity of informed consent was waived (protocol no. 17-326/C).

\section{Study variables}

Data were collected from the Dutch National Trauma Database for the area Central Netherlands. The following variables were collected: age, sex, trauma mechanism (from the International Classification of Diseases, 10th revision), ${ }^{14}$ Abbreviated Injury Scale (AIS) ${ }^{15}$ score and Injury Severity Score (ISS), ${ }^{16}$ vital signs (Glasgow Coma Scale (GCS) score, systolic blood pressure, respiratory rate, and saturation), and laboratory parameters (hemoglobin level, lactate, arterial blood gas parameters: $\mathrm{pH}$, $\mathrm{pCO}_{2}, \mathrm{pO}_{2}$, bicarbonate $\left(\mathrm{HCO}_{3}\right)$, base excess, and saturation).

Trauma mechanism data were further classified in the following groups: high-impact (collision of a car driver, cyclist, or pedestrian with a car or motorcycle) or low-impact (collision of a car driver, cyclist, or pedestrian with either a cyclist or pedestrian) traffic injuries, falling from high $(\geq 2 \mathrm{~m}$ ) or low height, penetrating injuries due to firearms or other causes, drowning, or inhalation trauma. The AIS score per region (head, thorax, abdomen, extremities) was categorized in low (AIS $\leq 2$ ), middle (AIS 3 ), and high $(\geq 4)$ severity. Neurotrauma was defined as head injury with an AIS score $\geq 3$. Brain injury according to the GCS score was categorized in minor $(\geq 13)$, moderate $(9-12)$, and severe $(\leq 8)$. This dichotomization is in line with a previous report. ${ }^{13}$

\section{Study outcomes}

The following outcome parameters were collected at the IMCU: admission duration, transfer location, indication for ICU transfer (if applicable), and in-hospital mortality. At the ICU, the outcome parameters were the admission duration, intubation duration, reason for ICU admission (if not intubated), post-ICU transfer location, and in-hospital mortality.

The costs per admission day (costs 2016) for the hospital ward, IMCU, and ICU were calculated by dividing the total annual costs of the unit by the annual number of admission days. These costs include all the overhead and operating costs (thereby excluding patient costs, such as radiography or laboratory costs). Due to business purposes and negotiations with insurance companies, exact costs per admission day were not given. Instead, the ratio of IMCU and ICU costs relative each other was used (ratio 3:5). The reimbursed fee per ICU day in the Netherlands in 2018 was used to obtain the approximate (hypothetical) costs of US\$1500 per IMCU and US\$2500 per ICU day.

\section{Statistical analyses}

Normally and non-normally distributed continuous variables were described with the mean and SD or the median and IQR, respectively. Categorical variables were described as numbers and proportions. As the aim of the study was descriptive rather than confirmative, no tests for statistical significance were performed. Total costs for all IMCU and ICU admissions were obtained by multiplying the admission days with the respective costs per admission day. All descriptive analyses were performed using $\mathrm{R}$ software for statistical computing (V.3.3.2.). ${ }^{17}$

\section{RESULTS}

An overview of the baseline characteristics of trauma admissions at the IMCU and ICU is provided in tables 1 and 2. A total of 1320 admissions were included, $675(51.1 \%)$ at the IMCUs and 645 (48.9\%) at the ICUs. Of the IMCU admissions, 324 (24.5\%) patients were admitted at the neuro(surgical) IMCU and 351 $(26.6 \%)$ at the mixed-surgical IMCU.

\section{Trauma admissions at both IMCUs}

Table 2 shows the baseline characteristics of the trauma admissions at both IMCUs. The transfers to the ICU $(n=38,5.6 \%)$ were admitted for a median of 28.1 hours (IQR 16.3-51.0) at the IMCU before subsequent ICU transfer. Indication for ICU transfer were mainly neurological deterioration or respiratory complications. Of these patients, four died during their hospital stay due to neurological herniation $(n=3)$ or cervical myelopathy $(n=1)$. During IMCU admission, one patient died from a neurogenic shock due to cervical spinal injury without treatment options and palliative care without ICU transfer was agreed on.

\section{Trauma admissions at the neuro(surgical) or mixed-surgical IMCU}

Table 3 shows the differences between the admission characteristics of admissions at the neuro(surgical) and mixed-surgical IMCU. The rate of subsequent ICU transfer was $6.2 \%(n=20)$ at the neuro(surgical) and $5.1 \%(n=18)$ at the mixed-surgical IMCU.

The indications for transfer from the IMCU to the ICU per type of IMCU are provided in table 4.

\section{Trauma admissions at the ICU}

Table 3 shows the characteristics of the trauma admissions at the ICU. Of the $24(3.7 \%)$ admissions that were not intubated, one received care which could not have been provided at the IMCU (non-invasive ventilation) whereas the others did not receive any ICU-specific care in this setting. These non-intubated admissions at the ICU were on average admitted for 18.3 hours (IQR 
Open access

Table 2 Differences between trauma admissions at the neuro(surgical) and mixed-surgical intermediate care unit

\begin{tabular}{|c|c|c|c|c|}
\hline \multirow{4}{*}{ General characteristics } & \multicolumn{2}{|c|}{ Neuro IMCU, n=324 } & \multicolumn{2}{|c|}{ Surgical IMCU, n=351 } \\
\hline & \multirow[t]{2}{*}{$\mathrm{n}(\%)$} & \multirow[t]{2}{*}{ Missing, n (\%) } & \multirow[t]{2}{*}{$\mathrm{n}(\%)$} & \multirow[t]{2}{*}{ Missing, $\mathrm{n}(\%)$} \\
\hline & & & & \\
\hline & $58.3(20.3)$ & $0(0.0 \%)$ & $50.3(20.0)$ & $0(0.0 \%)$ \\
\hline Sex, male (\%) & $212(65.4 \%)$ & $0(0.0 \%)$ & $250(71.2 \%)$ & $0(0.0 \%)$ \\
\hline \multicolumn{5}{|l|}{ Trauma mechanism } \\
\hline Traffic-HET & $82(25.3 \%)$ & $0(0.0 \%)$ & $169(48.1 \%)$ & $0(0.0 \%)$ \\
\hline Traffic-LET & $43(13.3 \%)$ & & $14(4.0 \%)$ & \\
\hline Fall—HET & $25(7.7 \%)$ & & $51(14.5 \%)$ & \\
\hline Fall—LET & $153(47.2 \%)$ & & $54(15.4 \%)$ & \\
\hline Penetrating-firearms & $1(0.3 \%)$ & & $6(1.7 \%)$ & \\
\hline Penetrating—other & $8(2.5 \%)$ & & $28(8.0 \%)$ & \\
\hline Burn/inhalation trauma & $0(0.0 \%)$ & & $14(4.0 \%)$ & \\
\hline Other & $12(3.7 \%)$ & & $15(4.3 \%)$ & \\
\hline \multicolumn{5}{|l|}{ Global injury severity } \\
\hline ISS (SD) & $18.1(8.4)$ & $0(0.0 \%)$ & $16.6(9.2)$ & $0(0.0 \%)$ \\
\hline \multicolumn{5}{|l|}{ Maximum AIS score } \\
\hline$\leq 3$ & $107(33.0 \%)$ & $0(0.0 \%)$ & $225(64.1 \%)$ & $0(0.0 \%)$ \\
\hline 4 & $178(54.9 \%)$ & & $110(31.3 \%)$ & \\
\hline $5-6$ & $39(12.0 \%)$ & & $16(4.6 \%)$ & \\
\hline \multicolumn{5}{|l|}{ Head injury severity } \\
\hline \multicolumn{5}{|l|}{ First ED GCS score } \\
\hline $14-15$ & $223(68.8 \%)$ & $25(7.7 \%)$ & $305(86.9 \%)$ & $28(8.0 \%)$ \\
\hline $9-12$ & $62(19.1 \%)$ & & $13(3.7 \%)$ & \\
\hline$\leq 8$ & $14(4.3 \%)$ & & $5(1.4 \%)$ & \\
\hline \multicolumn{5}{|l|}{ Maximum head AIS score } \\
\hline$\leq 2$ & $72(22.2 \%)$ & $0(0.0 \%)$ & $294(83.8 \%)$ & $0(0.0 \%)$ \\
\hline 3 & $50(15.4 \%)$ & & $34(9.7 \%)$ & \\
\hline $4-6$ & $202(62.3 \%)$ & & $23(6.6 \%)$ & \\
\hline \multicolumn{5}{|c|}{ Thoracoabdominal injury severity } \\
\hline \multicolumn{5}{|l|}{ Maximum thorax AIS score } \\
\hline$\leq 2$ & $273(84.3 \%)$ & $0(0.0 \%)$ & $166(47.3 \%)$ & $0(0.0 \%)$ \\
\hline 3 & $32(9.9 \%)$ & & $103(29.3 \%)$ & \\
\hline $4-6$ & $19(5.9 \%)$ & & $82(23.4 \%)$ & \\
\hline \multicolumn{5}{|c|}{ Maximum abdominal AIS score } \\
\hline$\leq 2$ & $322(99.4 \%)$ & $0(0.0 \%)$ & $312(88.9 \%)$ & $0(0.0 \%)$ \\
\hline 3 & $2(0.6 \%)$ & & $26(7.4 \%)$ & \\
\hline $4-5$ & $0(0.0 \%)$ & & $13(3.7 \%)$ & \\
\hline \multicolumn{5}{|l|}{ Extremity injury severity } \\
\hline \multicolumn{5}{|c|}{ Maximum extremity AIS score } \\
\hline$\leq 2$ & $307(94.8 \%)$ & $0(0.0 \%)$ & $263(74.9 \%)$ & $0(0.0 \%)$ \\
\hline 3 & $17(5.2 \%)$ & & $80(22.8 \%)$ & \\
\hline $4-5$ & $0(0.0 \%)$ & & $8(2.3 \%)$ & \\
\hline \multicolumn{5}{|c|}{ Vital signs at presentation (SD)[IQR] } \\
\hline Systolic blood pressure & $139(23.9)$ & $20(6.2 \%)$ & $136(25.2)$ & $9(2.6 \%)$ \\
\hline Respiratory rate & $19(5.3)$ & $66(20.4 \%)$ & $19(5.2)$ & $57(16.2 \%)$ \\
\hline Saturation & $1.00[0.97$ to 1.00$]$ & $30(9.3 \%)$ & $1.00[0.98$ to 1.00$]$ & $12[3.4 \%]$ \\
\hline \multicolumn{5}{|c|}{ Laboratory parameters at presentation (SD)[IQR] } \\
\hline Hemoglobin & $8.6[8.5$ to 8.7$]$ & $22(6.8 \%)$ & $8.7[8.6$ to 8.8$]$ & $16(4.6 \%)$ \\
\hline Lactate & $2.0[1.5$ to 2.9$]$ & $128(39.5 \%)$ & $1.9[1.4$ to 2.8$]$ & $80(22.8 \%)$ \\
\hline $\mathrm{pH}$ & $7.4[7.4$ to 7.4$]$ & $116(35.8 \%)$ & $7.4[7.3$ to 7.4$]$ & $58(16.5 \%)$ \\
\hline $\mathrm{pCO}_{2}$ & $40(7.8)$ & $116(35.8 \%)$ & $42(7.0)$ & $58(16.5 \%)$ \\
\hline $\mathrm{pO}_{2}$ & 154 [96 to 238$]$ & $116(35.8 \%)$ & 148 [88 to 243$]$ & $58(16.5 \%)$ \\
\hline
\end{tabular}


Table 2 Continued

\begin{tabular}{|c|c|c|c|c|}
\hline & \multicolumn{2}{|c|}{ Neuro IMCU, n=324 } & \multicolumn{2}{|c|}{ Surgical IMCU, n=351 } \\
\hline & $\mathrm{n}(\%)$ & Missing, $\mathrm{n}(\%)$ & $\mathrm{n}(\%)$ & Missing, $\mathrm{n}(\%)$ \\
\hline $\mathrm{HCO}_{3}$ & $24.2(3.0)$ & $116(35.8 \%)$ & $24.6(3.1)$ & $58(16.5 \%)$ \\
\hline $\mathrm{BE}$ & $0.0[-3.0$ to 2.0$]$ & $116(35.8 \%)$ & $0.0[-2.0$ to 2.0$]$ & $58(16.5 \%)$ \\
\hline Saturation & 1.00 [1.00 to 1.00$]$ & $129(39.8 \%)$ & 1.00 [1 to 1.00$]$ & $73(20.8 \%)$ \\
\hline
\end{tabular}

The numbers presented here are the descriptive statistics of intermediate care unit admissions after sustained trauma, stratified per intermediate care unit: the neuro(surgical) and mixed-surgical.

AIS, Abbreviated Injury Scale; BE, base excess; ED, emergency department; GCS, Glasgow Coma Scale; IMCU, intermediate care unit; ISS, Injury Severity Score.

11.5-23.7). They were transferred to the IMCU $(n=10)$, the hospital ward $(n=8)$, or discharged home $(n=6)$.

The ICU admissions without head injury were admitted for a median of 26.7 hours (14.6-111.8), of which $68.8 \%$ were admitted $\leq 72$ hours. These patients were intubated for a median of 15 (5.0-71.3) hours, of which $75.0 \% \leq 72$ hours. The ICU admissions after sustained severe head injury were admitted for a median of 65.3 hours (20.7-175.2), of which $52.5 \%$ were admitted $\leq 72$ hours. These patients were intubated for a median of $42.0(10.0-143.0)$ hours, of which $58.7 \% \leq 72$ hours.
Cost savings of the use of the IMCU

Total estimated expenditure was US\$2 659177 at the IMCU and US\$7 464417 at the ICU, with a total cost of US\$10 123594. If all trauma patients who were admitted to either one of the IMCUs would have been admitted to the ICU (eg, in the hypothetical scenario that our hospital would not have had IMCU care), this would lead to a total expenditure of US\$11 896378. The IMCU has thus potentially led to cost savings of US\$1 772 785 in the total period, that is, US\$393 952 per year.

Table 3 Trauma admissions at the intermediate and intensive care unit

\begin{tabular}{|c|c|c|}
\hline & IMCU & ICU \\
\hline Total admission, $\mathrm{n}$ & $\mathrm{n}=675$ & $\mathrm{n}=645$ \\
\hline \multicolumn{3}{|l|}{ Admission characteristics } \\
\hline Admission duration, median (IQR) & $32.8[18.8-62.5]$ & $46.7[16.8-155.5]$ \\
\hline Admissions < 72 h, n (\%) & $544(80.6)$ & $380(59.2 \%)^{*}$ \\
\hline \multicolumn{3}{|l|}{ Transfer characteristics } \\
\hline Hospital ward, n (\%) & $592(87.7)$ & $225(34.9 \%)$ \\
\hline Intermediate care unit, n (\%) & - & $324(50.4 \%)$ \\
\hline Intensive care unit, n (\%) & $38(5.6)$ & - \\
\hline Home, $n(\%)$ & $44(6.5)$ & - \\
\hline Death at the hospital unit, $\mathrm{n}(\%)$ & $1(0.1)$ & $95(14.8 \%)$ \\
\hline \multicolumn{3}{|l|}{ Indication ICU admission } \\
\hline Mechanical ventilation, $\mathrm{n}(\%)$ & - & $620(96.3 \%)$ \\
\hline No mechanical ventilation, $\mathrm{n}(\%)$ & - & $24(3.7 \%)$ \\
\hline Risk of intubation due to head injury & - & $5(0.8 \%)$ \\
\hline Risk of intubation due to airway obstruction & - & $3(0.5 \%)$ \\
\hline Risk of pulmonary deterioration & - & $3(0.5 \%)$ \\
\hline Hemodynamic monitoring for bleeding or cardiac contusion & - & $7(1.1 \%)$ \\
\hline Exchange bed (IMCU full)* & - & $6(0.9 \%)$ \\
\hline \multicolumn{3}{|l|}{ Indication ICU transfer } \\
\hline Postoperative after neurosurgical decompression, n (\%) & $9(1.3)$ & - \\
\hline Postoperative after rib fixation, $\mathrm{n}(\%)$ & $4(0.6)$ & - \\
\hline Postoperative after other operationst, $\mathrm{n}(\%)$ & $7(1.0)$ & - \\
\hline Intubation due to respiratory deterioration, $\mathrm{n}(\%)$ & $7(1.0)$ & - \\
\hline Intubation due to sepsis, n (\%) & $2(0.3)$ & - \\
\hline Intubation for other reasons $\ddagger, \mathrm{n}(\%)$ & $6(0.9)$ & - \\
\hline Respiratory support with non-invasive ventilation, $\mathrm{n}(\%)$ & $2(0.3)$ & - \\
\hline Multiple vasopressive medication, $\mathrm{n}(\%)$ & $1(0.1)$ & - \\
\hline In-hospital mortality, n (\%) & $23(3.4)$ & $134(20.8 \%)$ \\
\hline
\end{tabular}

The numbers presented are the indications, admission and transfer characteristics of intermediate care unit and intensive care unit admissions after sustained trauma.

*The exchange patients were admitted for other non-surgical disciplines due to full occupancy of their IMCU.

tCholecystectomy due to perforated gallbladder, stabilization of the spine, thoracotomy, pelvic fixation, femoral nail placement.

¥Atrial flutter, Guillain-Barré syndrome, combined respiratory and neurological deterioration, sedation to reduce the ICP, epileptic insult.

ICU, intensive care unit; IMCU, intermediate care unit. 
Table 4 Indications transfer from intermediate to intensive care unit (ICU) per intermediate care unit (neurosurgical and mixed-surgical)

\begin{tabular}{|llcc|}
\hline Indication ICU transfer, $\mathbf{n}(\%)$ & $\begin{array}{l}\text { Total } \\
(\mathbf{n}=38)\end{array}$ & $\begin{array}{l}\text { Neuro } \\
(\mathbf{n}=20)\end{array}$ & $\begin{array}{l}\text { Surgical } \\
(\mathbf{n}=18)\end{array}$ \\
\hline Postoperative & $20(52.6)$ & 10 & 10 \\
\hline Intubation due to respiratory deterioration & $7(1.04)$ & 5 & 2 \\
\hline Intubation due to sepsis & $2(0.30)$ & 1 & 1 \\
\hline Intubation for other reasons* & $6(0.89)$ & 2 & 4 \\
\hline Respiratory support with non-invasive ventilation & $2(0.30)$ & 1 & 1 \\
\hline Multiple vasopressive medication & $1(0.15)$ & 1 & 0 \\
\hline
\end{tabular}

*Atrial flutter, Guillain-Barré syndrome, combined respiratory and neurological deterioration, sedation to reduce the ICP, epileptic insult.

\section{DISCUSSION}

In the current study, half of the trauma patients in need of critical care were safely admitted at dedicated IMCUs. We also found that most ICU trauma admissions without severe neurotrauma are intubated only for a short time period ( $\leq 72$ hours). Further, the IMCU reduced the overall costs of critical trauma care.

In total, $51.1 \%$ of trauma critical care was provided at the IMCU. These admissions were major trauma patients (median ISS 17 (11-22)) of whom none died from preventable causes (ie, no deaths with respiratory or heamodynamic causes) after subsequent ICU transfer, indicating that this is a safe application of IMCUs. Combined with lower fixed costs at the IMCU this means that implementing the IMCU can substantially decrease the costs of overall provided care for trauma patients. ${ }^{11}$ This effect was indeed observed and could be explained by the graded requirements of supportive critical care: although most major trauma patients may require critical care, not all are in need of ICU admission. However, as the IMCU typically lacks maximum supportive capacities (eg, in our situation mechanical ventilation, intracranial pressure monitoring, and continuous renal replacement therapy), adequate triage and identification of the deteriorating patients are herein essential.

The majority of patients admitted at the ICU (96.3\%) received mechanical ventilation (eg, in major head injury), thus they were in need of specialized critical care therapy, which was not possible at the IMCU. However, many of these patients required only a short period of mechanical ventilation, as the intubation duration was $\leq 72$ hours in the majority of admissions $(65.2 \%$ in all and $75.0 \%$ in admissions without a head injury). This indicates that possibly, with the addition of the ability to ventilate trauma patients for a short time period, the majority of trauma patients in need of critical care could successfully be resuscitated in a dedicated unit. This supports the potential of a specialized trauma resuscitation unit, as described previously. ${ }^{13}$ Additional benefits could then be the direct involvement of both the trauma surgeon and the (trauma) anaesthesiologist and in-hospital centralization of specialized trauma critical care. ${ }^{13} 18$

To demonstrate the cost-efficiency of the IMCU, ideally a comparative study design is used to assess the effect of implementation (or dissemination) of the IMCU. Such designs include a cluster-randomized trial, stepped-wedged cluster randomized trial or an advanced before-after design. However, as there is a lack of evidence in this research field, we believe such studies should first be preceded by exploratory descriptive analyses such as presented here. Also, comparison of IMCU and ICU admissions with a propensity score analysis was not feasible due to the high rate of intubation at the ICU. From this, it follows that the populations are too different to warrant a matched analysis.
This study has several important practical implications. First, it supports the opening or maintaining of the IMCU to more precisely match hospitals' resources to patients in an economically efficient way. For example, a patient with a moderate head injury and a low (though not zero) risk of deterioration might not receive safe monitoring at the hospital ward, but does not require all the ICU resources. Second, it supports the possible implementation of specialized trauma care units in which trauma patients can shortly be mechanically ventilated.

Strengths of this study are that it is the first to show that critical trauma care can safely be provided at IMCUs. Also, it uses a large dataset obtained through a standardized data collection protocol over a 4.5 -year period. Additionally, this study is not limited to only the IMCU but also analyses the ICU, which provides a more comprehensive description of all relevant provided critical trauma care.

This study has several limitations. First of all, the generalizability of the results is subject to the organization of the trauma system as well as the in-hospital organization of trauma care delivery. Second, this study uses the ISS as a proxy for the requirement of critical care, assuming that patients with a high ISS at the IMCU also require critical care. Third, the validity of the cost savings calculation depends on two important assumptions. The first assumption is that all patients at the IMCU would - in the absence of the IMCU-have been admitted at the ICU. This seems reasonable to assume, as an earlier report at the same IMCU has shown that $>75 \%$ of patients at the IMCU received ICU care. This percentage is likely even higher in trauma patients, who frequently require a short period of monitoring. However, it is important to realize that if-in absence of the IMCU-all IMCU patients would have been admitted at the hospital ward, the IMCU would actually cost US\$1 772 785. The second assumption is that the average IMCU and ICU costs are representative for this trauma population, whom in reality may require (more or) less financial resources at the ICU than the average ICU patient. However, one should realize that $>80 \%$ of ICU (and IMCU) costs are fixed, and thus the variable costs are less important. ${ }^{19}$

\section{CONCLUSIONS}

A substantial amount of trauma patients in need of critical care can safely be admitted at the stand-alone specialist-driven IMCU, without the need for further mechanical ventilation. Thereby, the IMCU could fulfill an essential cost-saving role in the management of severely injured trauma patients.

Contributors JDJP made substantial contributions to design, data collection, data analysis, and interpretation. He was the main author involved in drafting and finalizing the manuscript. LMP was involved in the design, data interpretation and critically revised the manuscript. LPHL was involved in the design and critically revised the article. He has given final approval of this article to be published. FH contributed to the design and actively participated in data collection, analysis, and its interpretation. He was involved in drafting the article and revising it critically. He has given final approval of the version to be published.

Funding The authors have not declared a specific grant for this research from any funding agency in the public, commercial or not-for-profit sectors.

Competing interests None declared.

Patient consent Not required.

Ethics approval According to the Institutional Review Board, the study was not subject to the Medical Research Involving Human Subjects Act and therefore the necessity of informed consent was waived (protocol no. 17-326/C).

Provenance and peer review Not commissioned; externally peer reviewed.

Open access This is an open access article distributed in accordance with the Creative Commons Attribution Non Commercial (CC BY-NC 4.0) license, which permits others to distribute, remix, adapt, build upon this work non-commercially, 
and license their derivative works on different terms, provided the original work is properly cited, appropriate credit is given, any changes made indicated, and the use is non-commercial. See: http://creativecommons.org/licenses/by-nc/4.0/

\section{REFERENCES}

1. Celso B, Tepas J, Langland-Orban B, Pracht E, Papa L, Lottenberg L, Flint L. A systematic review and meta-analysis comparing outcome of severely injured patients treated in trauma centers following the establishment of trauma systems. J Trauma 2006;60:371-8

2. Moore L, Stelfox HT, Evans D, Hameed SM, Yanchar NL, Simons R, Kortbeek J, Bourgeois G, Clément J, Turgeon AF, et al. Trends in injury outcomes across Canadian trauma systems. JAMA Surg 2017;152:168-74.

3. Sampalis JS, Denis R, Lavoie A, Fréchette P, Boukas S, Nikolis A, Benoit D, Fleiszer D, Brown $R$, Churchill-Smith $M$, et al. Trauma care regionalization: a process-outcome evaluation. J Trauma 1999;46:565-81.

4. van Rein EAJ, van der Sluijs R, Houwert RM, Gunning AC, Lichtveld RA, Leenen LPH, van Heijl M. Effectiveness of prehospital trauma triage systems in selecting severely injured patients: is comparative analysis possible? Am J Emerg Med 2018;36:1060-9

5. Peitzman AB, Courcoulas AP, Stinson C, Udekwu AO, Billiar TR, Harbrecht BG. Trauma center maturation: quantification of process and outcome. Ann Surg 1999;230:87.

6. Faul M, Sasser SM, Lairet J, Mould-Millman NK, Sugerman D, staffing Tcenter. Trauma center staffing, infrastructure, and patient characteristics that influence trauma center need. West J Emerg Med 2015;16:98-106.

7. Jarman MP, Curriero FC, Haut ER, Pollack Porter K, Castillo RC. Associations of distance to trauma care, community income, and neighborhood median age with rates of injury mortality. JAMA Surg 2018:153:535.

8. Tepas JJ, Kerwin AJ, Ra JH. Unregulated proliferation of trauma centers undermines cost efficiency of population-based injury control. J Trauma Acute Care Surg 2014;76:576-81.
9. Pascoe H, Robertson D. Catheter-directed thrombolysis for acute limb ischaemia: an audit. Australas Med J 2014;7:471-5.

10. Plate JDJ, Leenen LPH, Houwert M, Hietbrink F. Utilisation of intermediate care units: a systematic review. Crit Care Res Pract 2017;2017:8038460.

11. Sjoding MW, Valley TS, Prescott HC, Wunsch H, Iwashyna TJ, Cooke CR. Rising billing for intermediate intensive care among hospitalized medicare beneficiaries between 1996 and 2010. Am J Respir Crit Care Med 2016;193:163-70.

12. de Grood C, Leigh JP, Bagshaw SM, Dodek PM, Fowler RA, Forster AJ, Boyd JM, Stelfox HT, Patient SHT. Patient, family and provider experiences with transfers from intensive care unit to hospital ward: a multicentre qualitative study. CMAJ 2018;190:E66 9-E676.

13. Nathens AB, Rivara FP, MacKenzie EJ, Maier RV, Wang J, Egleston B, Scharfstein DO, Jurkovich GJ. The impact of an intensivist-model ICU on trauma-related mortality. Ann Surg 2006;244:545-54.

14. World Health Organization. International statistical classification of diseases and related health problems. 10th revision. Geneva: World Health Organization, 2010

15. Medicine AftAoA. The abbreviated Injury Scale. Des Plaines, IL: Association for the Advancement of Automotive Medicine, 1990.

16. Baker SP, O'Neill B, Haddon W, Long WB. The injury severity score: a method for describing patients with multiple injuries and evaluating emergency care. J Trauma 1974;14:187-96.

17. R Core Team. R: a language and environment for statistical computing. Vienna, Austria: R Foundation for Statistical Computing, 2017.

18. Banks SE, Sharp C, Fouche YL, Haycock J, Dagal A. Considerations for anesthesia staffing in a trauma center: new standards, education, and safety. Curr Opin Anaesthesiol 2015:28:201-5.

19. Roberts RR, Frutos PW, Ciavarella GG, Gussow LM, Mensah EK, Kampe LM, Straus HE, Joseph G, Rydman RJ. Distribution of variable vs fixed costs of hospital care. JAMA 1999;281:644 